\title{
Sequencing and analyses on chloroplast genomes of Tetrataenium candicans and two allies give new insights on structural variants, DNA barcoding and phylogeny in Apiaceae subfamily Apioideae
}

\author{
Lu Kang ${ }^{1}$, Dengfeng Xie ${ }^{1}$, Qunying Xiao ${ }^{2}$, Chang Peng ${ }^{1}$, Yan Yu ${ }^{1}$, Xingjin He $^{\text {Corresp. } 1}$ \\ ${ }^{1}$ Key Laboratory of Bio-Resources and Eco-Environment of Ministry of Education, College of Life Sciences, Sichuan University, Chengdu, Sichuan, people's \\ republic of China \\ 2 College of Ecological Engineering, Guizhou University of Engineering Science, Bijie, Guizhou, China \\ Corresponding Author: Xingjin He \\ Email address: xjhe@scu.edu.cn
}

Background. Tetrataenium candicans is a traditional Chinese folk herbal medicine used in the treatment of asthma and rheumatic arthritis. Alongside several Tordyliinae species with fleshy roots, it is also regarded as a substitute for a Chinese material medicine called 'Danggui'. However, a lack of sufficient sampling and genomic information has impeded species identification and the protection of wild resources.

Methods. The complete chloroplast genomes of $T$. candicans from two populations, Tetrataenium yunnanense and Semenovia transilliensis, were assembled from two pipelines using data generated from next generation sequencing (NGS). Pseudogenes, inverted repeats (IRs) and hyper-variable regions were located by Geneious 11.1.5. Repeat motifs were searched using MISA and REPuter. DNA polymorphism and segment screening were processed by DNAsp5, and PCR product was sequenced with Sanger's sequencing method. Phylogeny was inferred by MEGA 7.0 and PhyML 3.0.

Results. The complete chloroplast genomes of $T$. candicans from two populations, $T$. yunnanense and $S$. transilliensis, were 142,261 bp, 141,985 bp, 142,714 bp and 142,145 bp in length, respectively, indicating conservative genome structures and gene categories. We observed duplications of trnH and psbA caused by exceptional contractions and expansions of the IR regions when comparing the four chloroplast genomes with previously published data. Analyses on DNA polymorphism located 29 candidate cp DNA barcodes for the authentication of 'Danggui' counterfeits. Meanwhile, 34 hypervariable markers were also located by the five Tordyliinae chloroplast genomes, and 11 of them were screened for population genetics of $T$. candicans based on plastome information from two individuals. The screening results indicated that populations of T.candicans may have expanded. Phylogeny inference on Apiaceae species by CDS sequences showed most lineages were well clustered, but the five Tordyliinae species failed to recover as a monophyletic group, and the phylogenetic relationship between tribe Coriandreae, tribe Selineae, subtribe Tordyliinae and Sinodielsia clade remains unclear.

Discussion. The four chloroplast genomes offer valuable information for further research on species identification, cp genome structure, population demography and phylogeny in Apiaceae subfamily Apioideae. 
1 Sequencing and analyses on chloroplast genomes of Tetrataenium candicans

2 and two allies give new insights on structural variants, DNA barcoding and

3 phylogeny in Apiaceae subfamily Apioideae

4

5

6 Lu Kang ${ }^{1}$, Dengfeng Xie ${ }^{1}$, Qunying Xiao ${ }^{2}$, Chang Peng ${ }^{1}$, Yan $\mathrm{Yu}^{1}$, Xinjin $\mathrm{He}^{1}$

$7{ }^{1}$ Key Laboratory of Bio-Resources and Eco-Environment of Ministry of Education, College of

8 Life Sciences, Sichuan University, Chengdu, Sichuan province, People's Republic of China

$9 \quad{ }^{2}$ College of Ecological Engineering, Guizhou University of Engineering Science, Bijie, GuiZhou

10 province, People's Republic of China

11 Corresponding Author:

12 Xinjin $\mathrm{He}^{1}$

13 Chengdu, Sichuan province, People's Republic of China

14 Email address: xjhe@scu.edu.cn 
41

42

43

44

45

46

47

48

49

50

51

52

53

54

55

56

57

58

59

60

61

62

63

64

65

66

67

68

69

70

71

72

73

74

75

76

77

78

79

80

\section{Abstract}

Background. Tetrataenium candicans is a traditional Chinese folk herbal medicine used in the treatment of asthma and rheumatic arthritis. Alongside several Tordyliinae species with fleshy roots, it is also regarded as a substitute for a Chinese material medicine called 'Danggui'. However, a lack of sufficient sampling and genomic information has impeded species identification and the protection of wild resources.

Methods. The complete chloroplast genomes of $T$. candicans from two populations, Tetrataenium yunnanense and Semenovia transilliensis, were assembled from two pipelines using data generated from next generation sequencing (NGS). Pseudogenes, inverted repeats (IRs) and hyper-variable regions were located by Geneious 11.1.5. Repeat motifs were searched using MISA and REPuter. DNA polymorphism and segment screening were processed by DNAsp5, and PCR product was sequenced with Sanger's sequencing method. Phylogeny was inferred by MEGA 7.0 and PhyML 3.0.

Results. The complete chloroplast genomes of $T$. candicans from two populations, $T$. yunnanense and $S$. transilliensis, were $142,261 \mathrm{bp}, 141,985 \mathrm{bp}, 142,714 \mathrm{bp}$ and $142,145 \mathrm{bp}$ in length, respectively, indicating conservative genome structures and gene categories. We observed duplications of $\operatorname{trn} H$ and $p s b A$ caused by exceptional contractions and expansions of the IR regions when comparing the four chloroplast genomes with previously published data. Analyses on DNA polymorphism located 29 candidate cp DNA barcodes for the authentication of 'Danggui' counterfeits. Meanwhile, 34 hyper-variable markers were also located by the five Tordyliinae chloroplast genomes, and 11 of them were screened for population genetics of $T$. candicans based on the plastome information from two individuals. The screening results indicated that populations of T.candicans may have expanded. Phylogeny inference on Apiaceae species by CDS sequences showed most lineages were well clustered, but the five Tordyliinae species failed to recover as a monophyletic group, and the phylogenetic relationship between tribe Coriandreae, tribe Selineae, subtribe Tordyliinae and Sinodielsia clade remains unclear.

Discussion. The four chloroplast genomes offer valuable information for further research on species identification, cp genome structure, population demography and phylogeny in Apiaceae subfamily Apioideae.

\section{Introduction}

Subtribe Tordyliinae is an Apiaceae lineage in tribe Tordylieae whose species are characterized by enlarged radiant outer petals and dorsally compressed fruits, with more than 15 incorporated genera (Fu, 1981; Xiao, 2017). Tetrataenium candicans var. candicans (Wall. ex DC.) Manden. is a perennial Tordyliinae herb endemic to the Qinghai-Tibet Plateau (QTP) and adjacent regions. They typically grow on sunny slopes and forest edges at elevations of about 2000 to 4200 meters, with dense white pubescence on the back side of leaves and prominent fruit 
81 ridges distinguishing them from other allied species $(F u, 1981)$. Our survey of the Chinese 82 Materia Medica resource inventory in Sichuan, Yunnan, Tibet and Qinghai province showed that $83 T$. candicans was a common herbal medicine used to treat asthma and rheumatic arthritis. 84 Moreover, alongside some Tordyliinae species with fleshy roots, it has been also widely used as 85 a substitute for 'Danggui,' a traditional Chinese medicine that was first recorded in "Shen 86 Nong's Herbal Classic" in about AD 200 to be used in blood enrichment and the treatment of 87 pulmonary diseases. However, since the misuse of the active ingredients in this species might 88 cause severe side effects (Sondhiaa et al, 2017; Zhang et al 2001), the Chinese Pharmacopoeia 89 Commission (2015) has restricted 'Danggui's' origin plant to Angelica sinensis (Oliv.) Diels 90 only. Additionally, the long growth cycle and over-exploitation of wild individuals used for medicinal and economic purposes has menaced the existence of T. candicans (Joshi and Dhar, 2003). Less attention was given to discriminate among the counterfeit 'Danggui' plants (especially from the subtribe Tordyliinae) which also delayed research on the drug's safety and discovery.

DNA barcoding is a common technique that aims to standardize DNA segments for specieslevel discrimination, and has been widely used in identification, taxonomy and biodiversity studies (Hodgetts et al ,2016; Chen et al, 2009; Devloo-Delva et al, 2010). The general procedure in developing DNA barcodes involves building public libraries of DNA segments from known species. The target sequences from an unknown species are then matched up with barcode libraries to search for best-matching species or close relatives (Hajibabaei et al, 2007). With the decline of sequencing cost in the past decades, a vast amount of DNA barcodes has been uploaded and retrieved. For instance, the $\mathrm{CO} 1$ gene is applied in the species recognition of animals and fungus (Seifert et al, 2007), while ITS, ITS2, psbA-trnH, matK and rbcL are effective in identifying Apiaceae species (Liu et al, 2014). Nevertheless, due to different substitution rates, hybridization, multiple copies and mutations, DNA barcodes are not applicable to all species (Kress and Erickson, 2007). For example, a universal barcode ycf15 (Gao et al, 2017) is absent in Coriandrum sativum (Peery, 2015), and species discrimination by ITS sequences are often flanked by hybridization (Liu et al, 2011). For these reasons, it is essential to develop specialized available DNA markers to protect and fully utilize local herbal resources.

The chloroplast (cp) is an important component in the plant cell as it is where optical energy can be restored in the form of carbohydrates through photosynthesis. As a semi-autonomous organelle, the chloroplast possesses uni-parental inherited cricoid DNA with a length ranging from $20.98 \mathrm{~kb}$ (Sciaphila densiflora) to $1320.6 \mathrm{~kb}$ (Haematococcus lacustris), presenting conservative gene locations and categories in flowering plants (Molina et al, 2014). Because of these features, chloroplast genomes have expanded our knowledge of genetic engineering (Daniell et al, 2016), phylogeny (Jansen et al, 2006) and population demography. With the development of next generation sequencing (NGS) and assembly technologies, the past two decades have witnessed more than $100 \mathrm{cp}$ genomes reportedly covering over 40 genera in 120 Apiaceae. These cp genomes are all characterized by a quadripartite structure similar to those of most angiosperms, and their discrepancies are mainly reflected in rare changes in gene order and 
121

122

123

124

125

126

127

128

129

130

131

132

133

134

135

136

137

138

139

140

141

142

143

144

145

146

147

148

149

150

151

152

153

154

155

156

157

158

159

160

shifting IR-LSC boundaries (Peery, 2015; Spooner et al, 2017). Although it is a monophyletic group (Logacheva et al, 2010) that is of important economic value, few studies have been devoted to the chloroplast genomes of Tordyliinae species.

In the present study, we reported cp genomes of two T. candicans individuals, Tetrataenium yunnanense (Xiao et al, 2017) and Semenovia transiliensis. By comparing them with published cp genomes, we explored the structural variation among Apiaceae species and located hypervariable cp DNA markers for Tordyliinae species and candidate cpDNA barcodes for the species identification of 'Danggui' counterfeits. Additionally, based on two cp genomes of $T$. candicans, $11 \mathrm{cpDNA}$ markers were screened to survey population diversity. Finally, phylogeny on 37 Apiaceae and Araliaceae species using CDS sequences of cp genomes was also inferred. This research will offer genomic and genetic information for future phylogenetic and phylogeographic studies on Tordyliinae, and will shed light on the protection and utilization of wild herbal medicine resources.

\section{Materials \& Methods}

\section{Plant materials and DNA sequencing}

Mature and healthy $T$. candicans leaves from two populations, $S$. transiliensis and $T$. yunnanense, were collected from Ganzi (Sichuan province, China; coordinates: $31^{\circ} 63^{\prime} \mathrm{N}$, $100^{\circ} 01^{\prime}$ E; approval number: XQY20150814001), Mu li (Sichuan province, China; coordinates: $28^{\circ} 40^{\prime} \mathrm{N}, 101^{\circ} 01^{\prime} \mathrm{E}$; approval number: KL20180620001), Tekesi (Xinjiang province, China; coordinates: $42^{\circ} 86^{\prime}$ N, $81^{\circ} 84^{\prime}$ E; approval number: XQY20160724008) and Lanping (Yunnan province, China; coordinates: $26^{\circ} 07^{\prime} \mathrm{N}, 9^{\circ} 85^{\prime} \mathrm{E}$; approval number: KL20180802001), respectively. All voucher specimens were deposited in the Sichuan University Herbarium (SZ). The total genomic DNA was isolated from dry leaves using an improved CTAB method (Doyle, 1987) and sequenced at Novogene (Novogene BioTech, Inc. Beijing, China) by Illumina Hiseq 2500 platform (Illumina, San Diego, CA). A genome skimming sequencing strategy (Steven et $a l, 2015)$ was performed to obtain deep coverage of organelle genomes regardless of the shallow sequencing of total genomic DNA. The coverage map was generated by Geneious 11.1.5.

\section{Quality control, genome assembly and genome annotation}

The quality of raw data was assessed by FastQC (v0.11.7 for windows) (Andrew et al, 2014). To accommodate the demands for data preparation of assembly software, we merely removed primers and adapters using Cutadapt v1.1.8 (Martin et al, 2011), and the qualified data was then assembled in different ways. Initially, a pipeline combining bowtie2-build (Langmead et al, 2012), SAMtools (Li et al, 2009), BEDtools (Quinlan et al, 2014) and SOAPdenovo 2 (Luo et al, 2012) was used to pick up reads that mapped to the best reference cp sequence. The consensus sequences were generated by Geneious 11.1.5 (Kearse et al, 2012) and gaps were filled by Sanger sequencing. For comparison, a seed-based assembler named NOVOPlasty 2.7.2 (Dierckxsens et al, 2017) was employed which eventually cyclized cp genomes.

New rules for annotating cp genomes of the four assembled cp genomes were also followed: (1) Geneious 11.1.5 was used for batch annotation of consensus sequences referring to annotations of Daucus carota (NC_008325) and Pastinaca pimpinellifolia (NC_027450); (2) 
161 Sequences were re-annotated on the DOGMA (Wyman et al, 2004) website to check for any

162

163

164

165

166

167

168

169

170

171

172

173

174

175

176

177

178

179

180

181

182

183

184

185

186

187

188

189

190

191

192

193

194

195

196

197

198

199

omissions and the identity was set above $70 \%$ in protein-coding genes, $80 \%$ in rRNA genes and 90\% in tRNA genes; (3) Pseudogenes were not marked, and incomplete homologous segments of a real gene (such as $p s b A, y c f 1$ ) were also regarded as pseudogenes; (4) tRNAscan-SE v2.0 (Lowe and Chan, 2016) was used for verifying tRNA genes. All annotation errors were manually corrected. Finally, the circular map was generated by OGDRAW (Lohse et al, 2013).

\section{Repeat motifs}

MISA (Thiel, 2003) was used for identifying simple sequence repeats (SSRs) of $T$. candicans, T. yunnanense, Heracleum moellendorffii, S. transiliensis and P. pimpinellifolia. The threshold was set as follows: the minimum repetitions of SSRs for mono-nucleotide, dinucleotides, tri-nucleotides, tetra-nucleotides, penta-nucleotide and hexa-nucleotides should be 10, 5, 4, 3, 3 and 3, respectively. Simple dispersed repeats (SDRs) were identified by Reputer (Kurtz, 2001). The minimal size of SDRs was $30 \mathrm{bp}$, and the similarity among SDRs should be no less than 90\%. IRA region and double-counting SDRs were removed.

\section{DNA polymorphism and candidate DNA barcodes}

To identify candidate DNA barcodes for the discrimination of 'Danggui' and local counterfeits, the cp genomes of T. candicans, T.yunnanense and five Selineae species (Angelica acutiloba (NC_029391) Angelica decursiva (KT781591), Angelica gigas (KX118044), Angelica laxifoliata (NC_040122) and A. sinensis (MH430891) were employed. DNA polymorphism of hyper-variable regions was calculated by DnaSP5 (Librado and Rozas, 2009). Before that, cpDNA segments were aligned by MAFFT v7.419 (Katoh et al, 2002) and trimmed manually. The genome variation was visualized using mVISTA (Frazer et al, 2004) by the ShuffleLAGAN alignment program (Brudno et al, 2003). The haplotype analysis, Tajima's test, and Fu and Li's test were processed by DNAsp5. Additionally, the DNA polymorphism of cp genomes of five Tordyliinae species (T. candicans, T. yunnanense, Heracleum moellendorffii, $S$. transiliensis and $P$. pimpinellifolia) was also calculated.

\section{Segment screening for $T$. candicans}

To investigate the population diversity of $T$. candicans in order to protect wild resources, we screened $11 \mathrm{cpDNA}$ segments from noncoding regions and designed primers using Geneious 11.1.5 based on hyper-variable regions of the two cp genomes of T. candicans. More than 30 populations were sampled covering most distributions on record, and each population sampled one or two individuals. Total genomic DNA was extracted by an improved CTAB method (Doyle, 1987). PCR amplification was carried out in a $30 \mu \mathrm{L}$ volume, and included $15 \mu \mathrm{L} \mathrm{ddH}_{2} \mathrm{O}$, $9 \mu \mathrm{L}$ mix (Tiangen, Beijing, China), $3 \mu \mathrm{L}$ DNA solution, $1.5 \mu \mathrm{L}$ Forward primer and $1.5 \mu \mathrm{L}$ reverse primer solution $\left(10 \mu \mathrm{mol} / \mathrm{L}^{-1}\right)$. The PCR procedure was as follows: pre-denaturation for 4 minutes at $94^{\circ} \mathrm{C}$, followed by 35 cycles of denaturation for 45 seconds at $94^{\circ} \mathrm{C}$, annealing at 50 $55^{\circ} \mathrm{C}$ for $1 \mathrm{~min}$ and extension at $72{ }^{\circ} \mathrm{C}$ for $1 \mathrm{~min}$, and finally, extension at $72^{\circ} \mathrm{C}$ for 7 minutes. The PCR products were sequenced (BGI, Beijing, China) by ABI 310 Genetic Analyzer (Applied Biosystems, Waltham, MA, USA). The paired-end sequences were assembled by

Peer] reviewing PDF | (2019:06:38210:2:0:NEW 10 Oct 2019) 
200 Geneious 11.1.5. DnaSP5 was available for nucleotide diversity, haplotype diversity, and 201 mismatching analyses.

202 Phylogeny reconstruction

203 Phylogenetic analysis was performed using concatenated alignments of 80 protein coding 204 sequences from 37 plastomes: A. sinensis (MH430891), Anethum graveolens (KR011055), 205 Angelica decursiva (KT781591), Angelica gigas (KX118044), Angelica laxifoliata (NC_041022), 206 Angelica polymorpha (NC_041580), Anthriscus cerefolium (GU456628), Arracacia 207 xanthorrhiza (KY117235), Bupleurum latissimum (KT983258), Caucalis platycarpos 208 (KX832334), Chuanminshen violaceum (KU921430), Cicuta virosa (NC_037711), Cnidium 209 officinale (MH121055), Coriandrum sativum (NC029850), Crithmum maritimum (HM596072), 210 Daucus carota (NC_008325), Dendropanax morbifer (KR136270), Foeniculum vulgare 211 (KR011054), Glehnia littoralis (KT153022), H. moellendorffii (MK210561), Hansenia forbesii 212 (KX808492), Ledebouriella seseloides (KT153021), Ligusticum sinense (KX594382), 213 Ligusticum tenuissimum (KT963039), Ostericum grosseserratum (KT852844), P. pimpinellifolia 214 (NC_027450), Petroselinum crispum (HM596073), Peucedanum japonicum (KU866530), 215 Pimpinella rhomboidea var. tenuiloba (MG719855), Pleurospermum camtschaticum 216 (KU041142), Prangos trifida (MG386251), Semenovia gyirongensis (NC_042912), Seseli 217 montanum (KM035851), S. transiliensis (MN267864), T. candicans (MK333395), Tiedemannia 218 filiformis subsp. greenmannii (HM596071), T. yunnanense (MN365275). Dendropanax morbifer 219 (KR136270) and Bupleurum latissimum (KT983258) were treated as outgroup. CDS sequences 220 were extracted by Geneious 11.1 .5 and aligned using the MAFFT plugin, with a proper manual 221 cutoff by MEGA 7.0 (Kumar et al, 2016). To avoid Long Branch Attraction (LBA) 222 (Huelsenbeck, 1997), Maximum likelihood (ML) estimation was performed for phylogeny 223 inference by online tool phyML 3.0 (Guindon et al, 2010) with 1000 bootstrap replicates, and the 224 best-fit model was GTR $+\mathrm{G}+\mathrm{I}$. Non-conserved loci were filtered by Gblocks $0.91 \mathrm{~b}$ (Talavera and 225 Castresana, 2007) with default parameters.

226 Results

227 Genome features of $T$. candicans, $S$. transiliensis and $T$. yunnanense

228 The sequences of two T. candicans, S. transiliensis and T. yunnanense, were 142,261 bp, $229141,948 \mathrm{bp}, 142,145 \mathrm{bp}$ and 142,714 bp in length, respectively, presenting typical quadripartite 230 structures containing a large single copy region (LSC) and a small single copy region (SSC) 231 jointed by two inverted repeats (IRA and IRB) (Fig. 1, coverage map in Fig. S1). The overall GC 232 content of the four cp genomes was $37.4 \%$ with an exception of $37.3 \%$ in $T$. yunnanense. The 233 GC content of the IR region was much higher than that of the other components, mainly because 234 tRNA and rRNA genes had aggregated at this region. The SSC region had the lowest GC content 235 in comparison with the remaining two components (Table 1).

236 The cp genomes of $T$. candicans, T. yunnanense and S. transiliensis contain 123 genes 237 (Table 2): 80 protein-coding genes, 35 tRNA genes and eight rRNA genes. There was no 238 protein-coding gene but five tRNA genes (trnA-UGC, trnH-GUG, trnI-GAU, trnN-GUU, trnR$239 A C G$ ) and four rRNA genes (rrn4.5, rrn5, rrn16, rrn23) were doubled in the IR regions. The 
240

241

242

243

244

245

246

247

248

249

250

251

252

253

254

255

256

257

258

259

260

261

262

263

264

265

266

267

268

269

270

271

272

273

274

275

276

277

278

279

SSC region included 11 protein-coding genes (ccs $A, n d h A, n d h D, n d h E, n d h F, n d h G, n d h H, n d h I$, $r p l 32, r p s 15, p s a C)$ and one tRNA gene $(\operatorname{trn} L-U A G)$, while the remaining 68 protein-coding genes and 24 tRNA genes occurred at the LSC region, with $y c f 1$ significantly straddling the SSC and IRA regions. There were 11 protein-coding genes $(a t p F, n d h A, n d h B, \operatorname{pet} B, \operatorname{pet} D, \operatorname{rpll} 6, \operatorname{rpl}$, rpoC1, rps12, rps16, ycf3) and six tRNA genes (trnA-UGC, trnG-UCC, trnI-GAU, trnK-UUU, $\operatorname{trnL}-U A A, \operatorname{trn} V-U A C$ ) that had introns, most of which had only one intron except for $c l p P, \operatorname{rps} 12$ and $y c f 3$. Coding regions of rps 12 were located across the LSC and two IR regions.

\section{Gene loss and pseudogenization}

Pseudogenes (marked with ' $\Psi$ ') were DNA segments that were homologous to real genes but had lost functionality to some extent (Vanin et al, 1985). Of the four assembled chloroplast genomes, $\psi$ ycf15 in T. candicans, T. yunnanense and S. transiliensis was formed through several small InDels (KU951523 was used as a reference sequence), while $\psi y c f 1$ and $\psi p s b A$ were generated through LSC-IR boundary shifting.

\section{LSC-IR / IR-SSC boundaries}

Taking the IRA-LSC boundary of tobacco as reference, junction type I', defined by Downie (Plunkett and Downie, 2000), was found in cp genomes of T. yunnanense, T. candicans and $S$. transiliensis. Meanwhile, a rare LSC-IR junction named F' was discovered in chloroplast genomes of $P$. pimpinellifolia (NC_027450) and H. moellendorffii (MK210561). The two junction types experienced extra expansion to $p s b A$, and the duplicated segment trnH-psbA inserted right behind old contracted LSC-IRB boundaries (Fig. 2).

While boundaries between the IR and LSC region were quite changeable, IRB-SSC and SSC-IRA junctions were highly conserved. All IRB-SSC boundaries of the four chloroplast genomes reported here were placed adjoined to $n d h F$, and the SSC-IRA boundaries located within the scope of $y c f l$. The Junction type definitions will contribute to further research on structural variations of cp genomes of Apiaceae species.

\section{SSRs and SDRs}

SSRs (Simple sequence repeats) correlated with multiple replications of motifs that contained one to six base pairs. Herein, we reported SSRs in cp genomes of the five Tordyllinae species that were longer than 10bp (Fig. 3, supplemental zip file SSRs.zip). Overall, 58, 64, 54, 52 and 70 SSRs were detected in T. candicans (MK333395), T. yunnanense, H. moellendorffii, $P$. pimpinellifolia and S. transiliensis, respectively (Fig. 3(A-E)). 'A/T'-rich mono-nucleotide SSRs were the most abundant microsatellites in all $\mathrm{cp}$ genomes, followed by 'AT/AT' di-nucleotide SSRs, while 'G/C'-rich SSRs were scarce. In T. candicans, 79.3\% (46) of SSRs were polyA, polyT or poly AT, and the proportions changed into $79.7 \%$ (51), 88.7\% (47), 78.8\% (41) and $81.4 \%$ (57) in T. yunnanense, $H$. moellendorffii, $P$. pimpinellifolia and $S$. transiliensis, respectively. Analyses on the distribution of different categories of SSRs in these five species suggested that the LSC region contains more SSRs than the SSC and IR regions. Repetitions of SSRs (Fig. 3E) in each cp genome were substantially in agreement and larger repeat units meant fewer replications. These SSRs can be potential markers for species discrimination, phylogeny and population studies for the five Tordyliinae species. 
280

281

282

283

284

285

286

287

288

289

290

291

292

293

294

295

296

297

298

299

300

301

302

303

304

305

306

307

308

309

310

311

312

313

314

315

316

317

318

319

SDRs (Short Dispersed Repeats) were more complex repeats longer than $30 \mathrm{bp}$. In this study, 24, 42, 27, 25, and 20 pairs of SDRs in cp genomes of T. candicans (MK333395), T. yunnanense, H. moellendorffii, P. pimpinellifolia and S. transiliensis were surveyed, respectively (Fig. S2, supplement zip file SDRs.zip). Forward (direct) SDRs were the most frequent repeats, followed by palindromic SDRs and reverse SDRs. Most SDRs were located at the intergenic regions; trnH-rrn 16 specifically was a hotspot area for SDRs in T. yunnanense with 15 pairs of SDRs dispersed in this region. There was no SDR longer than 60bp in $H$. moellendorffii, nor $P$. pimpinellifolia, while only two, two, and three SDRs longer than $60 \mathrm{bp}$ were observed in $T$. candicans, S. transiliensis and T. yunnanense, respectively. SDRs longer than 100bp only existed in T. yunnanense.

Additionally, SDRs accounting for the expansion of $\mathrm{cp}$ genomes through multiple replications were found in $S$. transiliensis and T. yunnanense. The $39 \mathrm{bp}$ SDRs that began at the $30419^{\text {th }}$ genome in S. transiliensis repeated three times in the LSC region. In T. yunnanense, SDRs that repeated more than twice occurred in the IR and LSC regions, with lengths of $30 \mathrm{bp}$ (six replications), $32 \mathrm{bp}$ (five replications) and $31 \mathrm{bp}$ (three replications). Particularly, the $125 \mathrm{bp}$ SDRs were considered novel insertions as they aligned any species with high similarities. This information on SDRs will be advantageous in exploring the structure evolution of chloroplast genomes.

\section{DNA polymorphism}

The visualization of cp genomes of seven species by mVISTA (Fig. 4) indicated that most hyper-variable DNA segments were situated at intergenic regions and introns, while CDS regions were much more conservative. DNA polymorphism of 67 hyper-variable regions were calculated with Pi values ranging from 0.00306 ( $p s b B$ ) to 0.03549 (trnH-psbA), with 38 sharing nucleotide diversity beyond 0.01, and 29 DNA segments able to discriminate each species (by number of haplotypes, Table S1). Beyond that, we also observed long insertions in three DNA segments ( $p s b A, n d h F-r p l 32$ and $n d h C$-trn $V$ ) exclusively existing in cp genomes of $A$. sinense. The 28 DNA segments (accD-ycf4, atpH-atpI, ccsA-ndhD, clpP intron2, intron, matK, ndhA $n d h C$-trnV, ndhF-rpl32, psbA-matK, psbE-petL, psbK-psbI, psbZ-rps14, rpl32-trnL, rpoB-trnC, rpoC1 intron, rpoC2-rpoC1, rps16 intron, rps16-trnQ, trnC-petN, trnE-trnT, trnG intron, trnHpsbA, trnK-rps 16, trnL-ndhJ, trnS-trnG, trnT-psbD, trnT-trnL, trnV-atpE) and segments with unique insertions could be candidate plastid DNA barcodes used in the authentication of counterfeit 'Danggui'.

DNA polymorphism of 106 intergenic regions and 19 introns, as well as 77 CDS in cp genomes of five Tordyliinae species, was also calculated. The nucleotide diversity value (pi) in CDS regions (Fig. S3) ranged from 0 to 0.013 with a mean of 0.0048 , which was much lower than that of intergenic regions (from 0 to 0.0681 , with a mean of 0.014 ) and introns (from 0 to 0.0142 , with a mean of 0.009). matK exhibited the highest DNA polymorphism in the CDS region with 42 polymorphic (segregating) loci detected. Of the 106 non-coding regions (Fig. 5), 65 DNA segments had DNA polymorphism values that exceeded 0.01 , with 42 segments longer than 200bp. Only seven introns had relatively high DNA polymorphism that exceeded 0.01 . 
320 Finally, according to length and number of polymorphism sites, 29 segments of non-coding

321

322

323

324

325

326

327

328

329

330

331

332

333

334

335

336

337

338

339

340

341

342

343

344

345

346

347

348

349

350

351

352

353

354

355

356

357

358

regions (accD-psaI, atpF intron, atpH-atpI, atpI-rps2, ccsA-ndhD, ndhA intron, ndhC-trnV, ndhF-rpl32, ndhG-ndhI, petA-psbJ, petN-psbM, psbA-matK, psbA-trnH, psbE-petL, psbK-psbI, psbM-trnD, psbZ-trG, rpl16 intron, rpoB-trnC, rps16 intron, rps16-trnQ, rps2-rpoC2, trnD-trnY, trnF-ndhJ, trnK-rps16, trnL-ndhB, trnL-trnF, trnQ-psbK, trnT-trnL) and five CDS (ccsA, matK, $n d h I, n d h G$ and $r p s 14$, ) regions were selected to be potential DNA markers used for further research.

\section{Segments screening for genetic diversity of $\boldsymbol{T}$. candicans}

All target DNA segments were successfully amplified and sequenced, except for sequencing failures in $n d h F-r p l 32$ and rpll6 intron caused by repeat sequences. These segments from different populations presented low DNA polymorphism below 0.01(Table S2), but significantly high haplotype diversity from $0.248(\operatorname{trnS}$-trn $G$ ) to 0.844 (rpll6 intron). Only four haplotypes were found in trnS-trnG and rpl16 intron alignments, while trnQ-rps 16 had the most haplotypes with 16. More than half of the haplotypes were private, indicating high haplotype diversity. Regarding mismatch analyses, all nine segments presented unimodal or smooth curves, indicating that the sampled populations (Table S3) had probably experienced recent expansion. However, the results were only confirmed by Tajima's test and Fu and Li's test against rps 16 intron, trnQ-rps 16, trnL-trnT, rps16-trnK (weak statistical significance), and trnS-trnG (weak statistical significance), while test result from rpll6 intron, $p s b A-\operatorname{trn} H, \operatorname{trnL}-F$ did not show statistical significance of deviation from zero.

\section{Phylogenetic inference}

Maximum Likelihood (ML) trees (Fig. 6) by 80 concatenated CDS sequences of 37 species from Apiaceae subfamily Apioideae were constructed, and most lineages were well supported. Bupleureae species experienced the earliest differentiation in the 12 clades, followed by species from tribe Pleurospermeae, Komarovia clade, tribe Oenantheae and tribe Scandiaceae. Seven clades or tribes from Apioid superclade clustered together with 100\% bootstrap support value, and Pyramidoptereae was sister to the remaining six clades. Within the subtribe Tordyllinae, lineage including $P$. pimpinellifolia and $H$. morllendorffii were closely clustered with $100 \%$ bootstrap support value. This lineage, together with species from tribe Selineae and Sinodielsia clade, constituted three parallel branches. Lineage composed of T. candicans, S. transiliensis, $T$. yunnanense and $C$. sativum was clustered with species from Sinodielsia clade with 100\% bootstrap support value. Phylogeny inference failed to recover the five Tordyliinae species as a monophyletic group.

\section{Discussion}

\section{Assembly methods and gene content}

In this study, four chloroplast genomes were assembled using genome skimming data based on the principle that organelle DNA have more copies than nrDNA in plant cells. The cp genomes of $T$. candicans, $S$. transiliensis and $T$. yunnanense were quadripartite with conservative gene organization and an almost halved length of IR regions that determined the selection of

Peer] reviewing PDF | (2019:06:38210:2:0:NEW 10 Oct 2019) 
359

360

361

362

363

364

365

366

367

368

369

370

371

372

373

374

375

376

377

378

379

380

381

382

383

384

385

386

387

388

389

390

391

392

393

394

395

396

397

398

assembly methods. From experience, seed-based assemblers (such as NOVOPlasty v 2.7.1) were more competent in assembling chloroplast genomes with contracted IR regions.

The four cp genomes contained 123 genes: 80 protein-coding genes, 35 tRNA genes and eight rRNA genes. Apart from truncated $p s b A$, only one pseudogene, $\psi y c f 15$, was observed, suggesting that gene content was highly conserved. 'ATG' was the start codon of most plastid genes, and illegal start codons occurred in $n d h D$, psbC and rps 19 in the four reported cp genomes. The translational initiation sites of $n d h D$ was ' $A C G$ ', which might be associated with a post-transcriptional ' $\mathrm{C}$ ' to ' $\mathrm{U}$ ' edit to improve the translating efficiency (Hirose et al,1999). The start codon of $p s b C$ was annotated as two distinct codons, namely 'GTG' in tobacco and 'ATG' in Apiaceae species, resulting from annotation preference as this gene was highly conservative in both tobacco and the four cp genomes, and 'ATG' was 33bp upstream of 'GTG'. 'ATG' was reported as a putative start codon of rps 19 in algae, while in angiosperms, the start codon turned into 'GTG', indicating an ancient mutation that may take place in a common ancestor.

\section{Molecular markers and segment screening for population genetics}

Based on the number of haplotypes and insertions, the 29 candidate cpDNA barcodes were able to distinguish 'Danggui' from the counterfeits, which gave new insight on discovering new candidate DNA barcodes using cp genomes. The 34 hypervariable DNA segments and SSRs in the five Tordyliinae species were also located. Our findings were consistent with previous conclusions that most SSRs were abundant in ' $\mathrm{A} / \mathrm{T}$ ' format, but the number of SSRs in the five cp genomes was much less than what had been reported in other species (Zhao et al,2018; Liu et al, 2018; Zong et al, 2019).

Additionally, we made attempts on segments screening for the genetic diversity of $T$. candicans through two cp genomes. All nine DNA segments exhibited high haplotype diversity with abundant private haplotypes, which might be explained by habitat fragmentation (Fahrig, 2003) of T. candicans in the Qinghai-Tibet plateau and adjacent regions, while low DNA polymorphism might be correlated to low substitution rate of cpDNA segment or rapid adaptive evolution (Zhao et al, 2013; Shi et al, 2015). What's more, recent expansion shown by mismatch analyses might give insight into why $T$. candicans are more likely to survive and be prosperous in its habitats. Those segments of high haplotype diversity could be genetic resources for population genetics and complement nrDNA barcodes in identifying producing areas of $T$. candicans.

\section{Dynamic IRA-LSC boundaries and repeat sequences}

Most angiosperms were highly conserved in the cp genome structure. As described in Nicotiana tabacum, a typical LSC-IRB $\left(\mathrm{J}_{\mathrm{LB}}\right)$ boundary occurred near rps 19. However, due to contraction or expansion at the IR regions, LSC-IRB or IRA-LSC boundaries could be really dynamic in Apiaceae. So far, 12 kinds of IRA-LSC boundaries were defined in the family Apiaceae (Plankett and Downie, 2000; Peery, 2015), among which type I' and F' were two rare junction types among land plants which existed only in cp genomes of tribe Coriandreae and Tordyliinae species in family Apiaceae.

There are several reported explanations for changes in the IR-LSC boundaries, including 
399 homologous recombination (Guo et al, 2014), double-strand break repair and the existence of 400 SDRs (Odom et al, 2008). A previous study on cp genomes of C. sativum supported double401 strand break repair (DBSR) by partial duplication of trnV-GAC and SDRs located within IR 402 regions that caused change in the IR boundary (Peery, 2015). However, the duplication of trnV$403 G A C$ was not observed in any Tordyliinae species. More interestingly, we observed some direct

404

405

406

407

408

409

410

411

412

413

414

415

416

417

418

419

420

421

422

423

424

425

426

427

428

429

430

431

432

433

434

435

436

437

438

SDRs located between $\operatorname{trn} H-G U G$ and $\operatorname{trnL}-C A A$, and between $\operatorname{trnH}-G U G$ and $\operatorname{rrn} 16$ in cp genomes of the five Tordyliinae species. These results indicated that changes in the LSC- IR boundary were far more complicated to be explained by a single mechanism. Additionally, some of the aforementioned SDRs (i.e. 125bp SDRs in T. yunnanense) are new insertions that are highly similar to nrDNA, mtDNA or mRNA segments. The novel insertions existed in the form of direct SDRs that might be preliminary evidence for intra-molecular recombination and foreign DNA transformation mediated by short direct-repeat sequences (Ogihara et al, 1988; Cai et al, 2008).

\section{Phylogeny inference}

In the past decades, phylogeny on the whole range of Apiaceae or subfamily Apioideae has been widely explored (Downie et al, 2000, 2004, 2010; Zhou et al, 2008, 2009), but few attempts have been made on utilizing plastid genomes for phylogeny inference. In such cases, protein coding sequences from 37 plastomes from 12 tribes in Apiaceae were employed for phylogeny inference as they were maternal inheritance, free of hybridization and had more informative loci (Daniell et al, 2016).

Reconstructed ML tree had 12 well stated tribes. The phylogenetic relationship of most tribes was in congruence with previous phylogenetic inferences using nrDNA datasets (Downie et al, 2010; Zhou et al, 2008, 2009). Ostericum koreanum (KT852844, marked as Ostericum grosseserratum in NCBI database), revised as Angelica reflexa (Lee et al, 2013), was distant from tribe Oenantheae, and the placement of L. tenuissimum and L. sinense in Sinodielsia clade by cp phylogenomics was also proven in Downie's research (Downie et al, 2010). Within subtribe Tordyliinae, T. candicans, T. yunnanense and S. transiliensis clustered as a lineage, while $H$. moellendorffii was closely related to $P$. pimpinellifolia, which supported the conclusion that both Pastinaca L. and Heracleum L. should be accepted into Heracleum sensu stricto clade (Logacheva et al, 2010; Xiao, 2017).

However, the five species from subtribe Tordylinae were not recovered as a monophyletic group on ML tree as studies using ITS and ETS sequences suggested (Downie et al, 2010; Zhou et al, 2008; Xiao, 2017; Logacheva et al, 2010). The possible reasons for phylogenetic incongruency were sampling errors, systematic errors and biological factors (Zou and Ge, 2008). Sampling errors (stochastic errors) and systematic errors were excluded first as causes for topological discordances as abundant informative loci existed in chloroplast genomes and no conspicuous long branch attraction (Bergsten, 2005) was observed (Philippe et al, 2005; Zhang et al, 2012). Biological factors referred to many aspects, such as horizontal gene transfer, ancient hybridization, incomplete lineage sorting, homoplasy and concert evolution (Koch et al, 2003). Even though very few intergeneric hybrids had been reported on Apiaceae species (Desjardins et

Peer) reviewing PDF | (2019:06:38210:2:0:NEW 10 Oct 2019) 
$439 a l, 2015 ;$ Yu et al, 2011), we suggested ancient hybridization cannot be excluded as most 440 Tordyliinae and Selineae species possessed the same base number of chromosomes $(\mathrm{n}=11)$ (He 441 and $\mathrm{Pu}$, 1994). Moreover, as shown in Fig. 6, short branches suggested that the disputed 442 phylogenetic relationship may also be explained by incomplete lineage sorting in Apiaceae 443 superclade Apioid that may had experienced rapid evolutionary radiation and species formation 444 (Calviño et al, 2008; Tamura et al, 2012) related to climate fluctuations or reproductive isolation 445 during Miocene (Liao et al, 2012; Wu et al, 2014; Banasiak et al, 2013). Nevertheless, further

446 analyses with more nuclear markers and samples from Tordylieae should be performed in order 447 to clarify this issue. Our research also indicated that chloroplast genomes were effective in 448 phylogeny inference, but may not be competent in dealing with conflicting phylogeny among 449 rapidly radiated species.

450

451

452

453

454

455

456

457

458

459

460

461

462

463

464

465

466

467

468

469

470

471

472

473

474

475

476

477

478

\section{Conclusions}

In this study, four cp genomes of two T. candicans individuals, $T$. yunnanense and $S$. transiliensis, were first reported. Analyses on genome structure revealed two kinds of rare simultaneous contractions and expansions of LSC-IR boundaries in assembled Tordyliinae cp genomes. The candidate cpDNA barcodes for the authentication of 'Danggui' and 34 hypervariable DNA segments in the five Tordyliinae cp genomes were also identified. Segment screening for population genetics of $T$. candicans suggested that populations had probably experienced recent expansion. Phylogeny inferences based on protein coding sequences from 37 plastomes of Apiaceae and Araliaceae species suggested that subtribe Tordyliinae was closely related with subtribe Selineae, tribe Coriandreae and Sinodielsias clade. However, ML tree failed to recover the five Tordyliinae species as a monophyletic group. On that basis, forthcoming research might focus on the structure variation of plastomes of Apiaceae species, cpDNA barcodes for 'Danggui' and phylogeny reconstruction at the genomic level by exploring efficient methods and increasing samples.

\section{Acknowledgments}

The authors thank the researchers who made advancements on the phylogeny of Apiaceae, and the publishers of related cp genome sequences in NCBI.

\section{References}

Andrew S. 2014. FastQC: a quality control tool for high throughput sequence data. Available at: http://www.bioinformatics.babraham.ac.uk/projects/fastqc/

Banasiak Ł, Piwczyński M, Uliński T, Downie, SR, Watson MF, Shakya B, Spalik K. 2013. Dispersal patterns in space and time: a case study of Apiaceae subfamily Apioideae. Journal of Biogeography 40(7):1324-1335.

Bergsten J. 2005. A review of long-branch attraction. Cladistics 21(2):163-193.

Brudno M, Malde S, Poliakov A, Do CB, Couronne O, Dubchak I, Batzoglou S. 2003. Glocal Alignment: Finding Rearrangements During Alignment. Bioinformatics 19S1: i54-i62.

Cai Z, Guisinger M, Kim HG, Ruck E, Blazier JC, McMurtry V, Kuehl JV, Boore J, Jansen RK .2008. Extensive reorganization of the plastid genome of Trifolium subterraneum 
479

480

481

482

483

484

485

486

487

488

489

490

491

492

493

494

495

496

497

498

499

500

501

502

503

504

505

506

507

508

509

510

511

512

513

514

515

516

517

(Fabaceae) is associated with numerous repeated sequences and novel DNA insertions. J Mol Evol 67:696-704.

Calviño CI, Martínez SG, Downie SR. 2008. The evolutionary history of Eryngium (Apiaceae, Saniculoideae): rapid radiations, long distance dispersals, and hybridizations. Molecular Phylogenetics and Evolution 46(3):1129-1150.

Chen SL, Song JY, Hui Y, Shi LC, Luo K, Han JP. 2009. Strategy and key technique of identification of Chinese herbal medicine using DNA barcoding. Chinese Journal of Natural Medicines 7(5):322-327.

Chinese Pharmacopoeia Commission. 2015. The Pharmacopoeia of the People's Republic of China, 2015 Edition Part I. Beijing: China Medical Science Press.

Daniell H, Lin CS, Ming Y, Chang WJ. 2016. Chloroplast genomes: diversity, evolution, and applications in genetic engineering. Genome Biology 17(1):134.

Desjardins SD, Leslie AC, Stace CA, Schwarzacher T, Bailey JP. 2015. Intergeneric hybridisation between Berula erecta and Helosciadium nodiflorum (Apiaceae). Taxon 64(4):784-794.

Devloo-Delva F, Miralles L, Ardura A, Borrell YJ, Pejovic I, Tsartsianidou V, Garcia-Vazquez E. 2016. Detection and characterization of the bio-pollutant Xenostrobus securis (Lamarck 1819) Austrian population from DNA barcoding and eBarcoding. Marine Pollution Bulletin 105(1):23-29.

Dierckxsens N, Mardulyn P, Smits G.2017. NOVOPlasty: denovo assembly of organelle genomes from whole genome data. Nucleotide Acids Research Vol.45, No.4, e18.

Downie SR, Downie DS, Watson MF. 2000. A phylogeny of the flowering plant family Apiaceae based on chloroplast DNA rpll6 and rpoC1 intron sequences: towards a suprageneric classification of subfamily Apioideae. American Journal of Botany 87(2):273.751.

Downie SR, Sun FJ, Katzdownie DS, Colletti GJ. 2004. A phylogenetic study of Perideridia (Apiaceae) based on nuclear ribosomal DNA its sequences. Systematic Botany 29(3):737.

Downie SR., Spalik K, Katzdownie DS, Reduron JP. 2010. Major clades within Apiaceae subfamily Apioideae as inferred by phylogenetic analysis of nrDNA its sequences. Plant Diversity and Evolution 128(1):111-136.

Doyle JJ. 1987. A rapid DNA isolation procedure for small quantities of fresh leaf tissue. Phytochemical Bulletin 19:11-15.

Fahrig, L. 2003. Effects of habitat fragmentation on biodiversity. Annual Review of Ecology Evolution and Systematics 34(2):487-515.

Frazer KA, Pachter L, Poliakov A, Rubin EM, Dubchak I. 2004. VISTA: computational tools for comparative genomics. Nucleotide Acids Research W273-9.

Fu KJ. Umbelliferae. Flora Tsinlingenisis. (Spermatophyta). 1981. Science Press 1(3).

Gao NN, Zhao ZL, Ni LH. 2017. Prospect: Identification of medicinal plant based on chloroplast gene ycf15. Chinese Traditional and Herbal Drugs 2017-15.

PeerJ reviewing PDF | (2019:06:38210:2:0:NEW 10 Oct 2019) 
518 Guindon S, Dufayard JF, Lefort V, Anisimova M, Hordijk W, Gascuel O. 2010. New Algorithms 519 and Methods to Estimate Maximum-Likelihood Phylogenies: Assessing the Performance of

520

521

522

523

524

525

526

527

528

529

530

531

532

533

534

535

536

537

538

539

540

541

542

543

544

545

546

547

548

549

550

551

552

553

554

555

556 PhyML 3.0. Systematic Biology 59(3):307-21

Guo WH, Grewe F, Cobo-Clark A, Fan WS, Duan ZL, Adams RP, Schwarzbach AE, Mower JP. 2014. Predominant and substoichiometric isomers of the plastid genome coexist within juniperus plants and have shifted multiple times during cupressophyte evolution. Genome Biology and Evolution 6(3):580-590.

Hajibabaei M, Singer GAC, Hebert PDN, Hickey DA. 2007. DNA barcoding: how it complements taxonomy, molecular phylogenetics and population genetics. Trends in Genetics 23(4):167-172.

He XJ, Pu FT, Wang LP. 1994. Studies on karyotypes of the genus Heracleum from china. Acta Phytotaxonomica Sinica 32(1):32-40. (in Chinese)

Hirose T, Kusumegi T, Tsudzuki T, Sugiura M. 1999. RNA editing sites in tobacco chloroplast transcripts: editing as a possible regulator of chloroplast RNA polymerase activity. Molecular and General Genetics 262(3):462-467.

Hodgetts J, Ostojã-Starzewski JC, Prior T, Lawson R., Hall J, Boonham N. 2016. DNA barcoding for biosecurity: case studies from the UK plant protection program. Genome, 59(11):1033-1048.

Huelsenbeck JP. 1997. Is the Felsenstein Zone a Fly Trap? Systematic Biology 46(1):69-74.

Jansen RK, Kaittanis C, Saski C, Lee SB, Tomkins J, Alverson AJ, Daniell H. 2006. Phylogenetic analyses of Vitis (vitaceae) based on complete chloroplast genome sequences: effects of taxon sampling and phylogenetic methods on resolving relationships among rosids. Bmc Evolutionary Biology 6(1):32.

Joshi M, Dhar U.2003. Effect of various presowing treatments on seed germination of Heracleum candicans Wall, ex DC. A high value medicinal plant. Seed Science and Technology 31(3):737-743.

Katoh K, Misawa K, Kuma K, Miyata T. 2002. MAFFT: a novel method for rapid multiple sequence alignment based on fast Fourier transform. Nucleotide Acids Research 44: W5457.

Kearse M, Moir R, Wilson A, Stones-Havas S, Cheung M, Sturrock S, Buxton S, Cooper A, Markowitz S, Duran C, Thierer T, Ashton B, Meintjes P, Drummond A. 2012. Geneious basic:an integrated and extendable desktop software platform for the organization and analysis of sequence data. Bioinformatics 28:1647-1649.

Koch M. A, Dobes C, Thomas M. O. 2003. Multiple hybrid formation in natural populations: concerted evolution of the internal transcribed spacer of nuclear ribosomal dna (its) in north american arabis divaricarpa (brassicaceae). Molecular Biology and Evolution, 20(3):338350.

Kress WJ, Erickson DL. 2007. A two-locus global DNA barcode for land plants: the coding $r b c L$ gene complements the non-coding trnH-psbA spacer region. PLoS One 2(6):e508. 
557 Kumar S, Stecher G, Tamura K. 2016. MEGA7: molecular evolutionary genetics analysis

558

559

560

561

562

563

564

565

566

567

568

569

570

571

572

573

574

575

576

577

578

579

580

581

582

583

584

585

586

587

588

589

590

591

592

593

594

595

596 version 7.0 for bigger datasets. Molecular Biology and Evolution 33:1870-1874.

Kurtz S, Choudhuri JV, Ohlebusch E, Schleiermacher C, Stoye J, Giegerich R. 2001. REPuter: The manifold applications of repeat analysis on a genomic scale. Nucleic Acids Research 29:4633-4642.

Langmead B, Salzberg S. 2012.Fast gapped-read alignment with Bowtie 2. Nature Methods 9:357-359.

Lee BY, Kwak MH, Han JE, Jung EH, Nam GH. 2013. Ganghwal is a new species, Angelica reflexa. Journal of Species Research 2:245-248.

Li H, Handsaker B, Wysoker A, Fennell T, Ruan J, Homer N, Marth G, Abecasis G, Durbin R, 1000 Genome Project Data Processing Subgroup. 2009. The Sequence alignment/map (SAM) format and SAMtools. Bioinformatics 25:2078-2079.

Liao CY, Downie SR, Yu Y, He XJ. 2012. Historical biogeography of the Angelica group (Apiaceae tribe Selineae) inferred from analyses of nrDNA and cpDNA sequences. Journal of Systematics and Evolution 50:1759-6831.

Librado P, Rozas J. 2009. DnaSP v5: A software for comprehensive analysis of DNA polymorphism data. Bioinformatics 25:1451-1452.

Liu J, Shi L, Han J, Li G, Lu H, Hou J, Zhou X, Meng F, Downie SR. 2014. Identification of species in the angiosperm family Apiaceae using DNA barcodes. Molecular Ecology Resources 14(6):1231-1238.

Liu L, Wang Y, He P, Li P, Fu CX. 2018. Chloroplast genome analyses and genomic resource development for epilithic sister genera Oresitrophe and Mukdenia (Saxifragaceae), using genome skimming data. BMC Genomics 19(1):235.

Liu YJ, Liu Y, Huang YJ, Long CL. 2011. Progress and application of DNA barcoding technique in plants. Journal of plant resources and environment 20(1):74-82, 93.

Logacheva MD, Valiejo-Roman CM, Degtjareva GV, Stratton JM, Downie SR, Samigullin TH, Pimenov MG. 2010. A comparison of nrDNA ITS and ETS loci for phylogenetic inference in the Umbelliferae: an example from tribe Tordylieae. Molecular Phylogenetics Evolution 57(1):471-476.

Lohse M, Drechsel O, Kahlau S, Bock R. 2013. Organellar Genome DRAW-a suite of tools for generating physical maps of plastid and mitochondrial genomes and visualizing expression data sets. Nucleic Acids Research 41:W575-W581.

Lowe TM, Chan PP. 2016. tRNAscan-SE On-line: Search and Contextual Analysis of Transfer RNA Genes. Nucleotide Acids Research 44:W54-57. Available at: http:// http://lowelab.ucsc.edu/tRNAscan-SE/

Luo R, Liu B, Xie Y, Li Z, Huang W, Yuan J, He G, Chen Y, Pan Q, Liu Y, Tang J, Wu G, Zhang H, Shi Y, Liu Y, Yu C, Wang B, Lu Y, Han C, Cheung DW, Yiu SM, Peng S, Xiaoqian Z, Liu G, Liao X, Li Y, Yang H, Wang J, Lam TW, Wang J. 2012. Soapdenovo2: an empirically improved memory-efficient short-read de novo assembler. Gigascience 1: 18. Martin M. 2011. Cutadapt removes adapter sequences from high-throughput sequencing reads. 
597

598

599

600

601

602

603

604

605

606

607

608

609

610

611

612

613

614

615

616

617

618

619

620

621

622

623

624

625

626

627

628

629

630

631

632

633

634

635

EMBnet Journal 17(1):10-12.

Molina J, Hazzouri KM, Nickrent D, Geisler M, Meyer RS, Pentony MM, Flowers JM, Pelser P, Barcelona J, Inovejas SA, Uy I, Yuan W, Wilkins O, Michel CI, LockLear S, Concepcion GP, Purugganan MD. 2014. Possible Loss of the Chloroplast Genome in the Parasitic Flowering Plant Rafflesia lagascae (Rafflesiaceae). Molecular Biology and Evolution, 31(4):793-803.

Odom OW, Baek KH, Dani RN, Herrin DL. 2008. Chlamydomonas chloroplasts can use short dispersed repeats and multiple pathways to repair a double-strand break in the genome. The Plant Journal 53(5):842-853.

Ogihara Y, Terachi T, Sasakuma T. 1988. Intramolecular recombination of chloroplast genome mediated by short direct-repeat sequences in wheat species. Proceedings of the National Academy of Sciences of the United States of America 85(22):8573-8577.

Peery, R. 2015. Understanding angiosperm genome interactions and evolution: insights from sacred lotus (Nelumbo nucifera) and the carrot family (Apiaceae). Thesis in PhD, 66-82.

Philippe H, Zhou Y, Brinkmann H, Rodrigue N, Delsuc F. 2005. Heterotachy and long-branch attraction in phylogenetics. Bmc Evolutionary Biology 5(1):1-8.

Plunkett GM, Downie SR. 2000. Expansion and contraction of the chloroplast inverted repeat in Apiaceae subfamily Apioideae. Systematic Botany 25:648-667.

Quinlan AR. 2014. Bedtools: the swiss-army tool for genome feature analysis. Current Protocols in Bioinformatics 47.11.12.1.

Seifert KA, Samson RA, Dewaard JR, Houbraken J, Lévesque CA, Moncalvo JM. 2007. Prospects for fungus identification using CO1 DNA barcodes, with Penicillium as a test case. Proceedings of the National Academy of Sciences of the United States of America 104(10):3901-3906.

Shi XJ, Zhang ML. 2015. Phylogeographical structure inferred from cpDNA sequence variation of Zygophyllum Xanthoxylon across north-west china. Journal of Plant Research 128(2):269-282.

Sondhiaa S, Duke SO, Green S, Gemejiyeva NG, Mamonov LK. Cantrellb CL. 2017. Phytotoxic Furanocoumarins from the Shoots of Semenovia transiliensis. Natural Product Communications 7(10):1327-1330.

Spooner DM, Ruess H, Iorizzo M, Senalik D, Simon P. 2017. Daucus littoralis: data from entire plastid phylogeny of the carrot genus (Daucus, Apiaceae): concordance with nuclear data and mitochondrial and nuclear DNA insertions to the plastid. American Journal of Botany 104(2):296.

Steven D. 2015. Genome skimming for next-generation biodiversity analysis. Trends in Plant Science, 20(9):525-527.

Talavera G, Castresana J. 2007. Improvement of phylogenies after removing divergent and ambiguously aligned blocks from protein sequence alignments. Systematic Biology 56(4):564-577. Available at: http://www.phylogeny.fr/one_task.cgi? task_type=gblocks/ 
636 Tamura K., Battistuzzi FU, Billing RP, Murillo O, Filipski A, Kumar S. 2012. Estimating

637

638

639

640

641

642

643

644

645

646

647

648

649

650

651

652

653

654

655

656

657

658

659

660

661

662

663

664

665

666

667

668

669

670

671

672

673

Divergence Times in Large Molecular Phylogenies. Proceedings of the National Academy of Sciences of the United States of America 109:19333-19338.

Thiel T, Michalek W, Varshney R, Graner A. 2003. Exploiting EST databases for the development and characterization of gene derived SSR-markers in barley (Hordeum vulgare L.). Theoretical and Applied. Genetics 106:411-422.

Vanin EF. 1985. Processed pseudogenes: characteristics and evolution. Annual Review of Genetics 19:253-72.

Wu H, Guo Z, Guiot J, Hatté C, Peng C, Yu YY, Ge JY, Peng CH, Li Q, Sun AZ, Zhao DA. 2014. Elevation-induced climate change as a dominant factor causing the late miocene C-4 plant expansion in the himalayan foreland. Global Change Biology 20(5):1461-1472.

Wyman SK, Jansen RK, Boore JL. 2004. Automatic annotation of organelle genomes with DOGMA. Bioinformatics 20(17):3252-3255.

Xiao QY. Phylogeny of subtribe Tordyliinae (Apiaceae tribe Tordylieae) in China. 2017. D. Phil. Thesis, Sichuan university.

Xiao QY, Yu Y, Xie DF, Guo XL, He XJ. 2017. Taxonomic revision of angelica oncosepala and heracleum yunnanense. Nordic Journal of Botany.

Yu Y, Downie SR, He XJ, Deng X, Yan L. 2011. Phylogeny and biogeography of Chinese Heracleum (Apiaceae tribe Tordylieae) with comments on their fruit morphology. Plant Systematics and Evolution 296(3-4):179-203.

Zhang QZ, Wang KJ, Hu MH. 2001. Pharmacognostic studies on root of Heracleum candicans. Chinese Traditional and Herbal Drugs 32(7):648-649.

Zhang YX, Zeng CX, Li DZ. 2012. Complex evolution in Arundinarieae (Poaceae: Bambusoideae): incongruence between plastid and nuclear gbssi gene phylogenies. Molecular Phylogenetics and Evolution 63(3):0-797.

Zhao C, Wang CB, Ma XG, Liang QL, He XJ. 2013. Phylogeographic analysis of a temperatedeciduous forest restricted plant (Bupleurum longiradiatum turcz.) reveals two refuge areas in china with subsequent refugial isolation promoting speciation. Molecular Phylogenetics and Evolution 68(3):628-643.

Zhao Z, Wang X, Yu Y, Yuan S, Jiang D, Zhang Y, Zhang T, Zhong W, Yuan Q, Huang L. 2018. Complete chloroplast genome sequences of Dioscorea: Characterization, genomic resources, and phylogenetic analyses. PeerJ 6:e6032.

Zhou J, Peng H, Downie SR, Liu ZW, Gong X. 2008. A molecular phylogeny of Chinese Apiaceae subfamily Apioideae inferredfrom nuclear ribosomal DNA internal transcribed spacer sequences. Taxon 57:402-416.

Zhou J, Gong X, Downie SR., Peng H. 2009. Towards a more robust molecular phylogeny of Chinese Apiaceae subfamily Apioideae: additional evidence from nrDNA ITS and cpDNA intron (rpl16 and rps 16) sequences. Molecular Phylogenetics and Evolution 53:56-58.

Peer) reviewing PDF | (2019:06:38210:2:0:NEW 10 Oct 2019) 
674 Zong D, Zhou A, Zhang Y, Zou X, Li D, Duan A, He C. 2019. Characterization of the complete 675 chloroplast genomes of five Populus species from the western Sichuan plateau, southwest $676 \quad$ China: comparative and phylogenetic analyses. PeerJ, 7:e6386.

677 Zou XH, Ge S. 2008. Conflicting gene trees and phylogenomics. Journal of Systematics and 678 Evolution 46:795-807. (in Chinese) 


\section{Table 1 (on next page)}

Sampling and genome information of four assembled cp genomes

The average coverage of each cp genomes was calculated by formula: (mapped reads $* 150$ ) / length of cp genome. 
1

\begin{tabular}{ccccc}
\hline & S. transiliensis & T. candicans & T. candicans & T. yunnanense \\
\hline Genebank No. & MN267864 & MK333395 & MK522402 & MN365275 \\
Length of Genome(bp) & 142,143 & 142,261 & 141,948 & 142,714 \\
Mean coverage (X) & 1805 & 3371 & 187 & 908 \\
Raw data (GB) & 17.6 & 16.3 & 5.1 & 26.6 \\
GC content (\%) & 37.4 & 37.4 & 37.4 & 37.3 \\
LSC length (bp) & 100,072 & 99,569 & 99,961 & 100,000 \\
LSC GC content (\%) & 36.1 & 36.1 & 36.1 & 36.0 \\
SSC length (bp) & 17,513 & 17,536 & 17,533 & 17,514 \\
SSC GC content (\%) & 31.1 & 31.1 & 31.1 & 30.9 \\
IR length (bp) & 12,279 & 12,578 & 12,227 & 12,600 \\
IR GC content (\%) & 47.1 & 47.1 & 47.1 & 46.8 \\
CDS length(bp) & 68,586 & 68,577 & 68,561 & 65,044 \\
CDS GC content (\%) & 37.8 & 37.9 & 37.9 & 37.9 \\
Protein coding genes & 80 & 80 & 80 & 80 \\
tRNAs & 35 & 35 & 35 & 35 \\
rRNAs & 8 & 8 & 8 & 8 \\
Total genes & 123 & 123 & 123 & 123 \\
\hline
\end{tabular}

2 
Table 2 (on next page)

Genes and categories in the four assembled Tordyliinae cp genomes

Doubled genes are marked with asterisks $(*)$. 
1

\begin{tabular}{|c|c|c|c|c|c|c|c|}
\hline Groups & Categories & & & Name of gene & & & \\
\hline \multirow[t]{11}{*}{ Self-replication } & rRNAs & $\operatorname{rrn} 4.5^{*}$ & $\operatorname{rrn} 5 *$ & $\operatorname{rrn} 16^{*}$ & $\operatorname{rrn} 23^{*}$ & & \\
\hline & \multirow[t]{5}{*}{ tRNAs } & $\operatorname{trn} Y-G U A$ & $\operatorname{trn} W-C C A$ & $\operatorname{trn} V-U A C$ & $\operatorname{trn} V-G A C$ & $\operatorname{trn} T-U G U$ & $\operatorname{trn} T-G G U$ \\
\hline & & $\operatorname{trn} S-U G A$ & $\operatorname{trn} S-G G A$ & $\operatorname{trn} S-G C U$ & $\operatorname{trn} R-U C U$ & $\operatorname{trn} R-A C G^{*}$ & $\operatorname{trn} Q-U U G$ \\
\hline & & $\operatorname{trn} P-U G G$ & $\operatorname{trnN}-G U U^{*}$ & $\operatorname{trnM}-C A U^{*}$ & $\operatorname{trn} L-U A G$ & $\operatorname{trnL} L-U A A$ & $\operatorname{trn} L-C A A$ \\
\hline & & $\operatorname{trn} K-U U U$ & $\operatorname{trnI}-G A U^{*}$ & $\operatorname{trnI}-C A U$ & $\operatorname{trn} H-G U G^{*}$ & $\operatorname{trn} G-U C C^{*}$ & $\operatorname{trn} F-G A A$ \\
\hline & & $\operatorname{trn} E-U U C$ & $\operatorname{trn} D-G U C$ & & & & \\
\hline & \multirow[t]{2}{*}{ Small subunit of ribosome } & $r p s 2$ & rps3 & rps 4 & rps 7 & rps 8 & rps11 \\
\hline & & rps 12 & rps14 & $\operatorname{rps} 15$ & rps16 & rps 18 & rps19 \\
\hline & \multirow[t]{2}{*}{ Large subunit of ribosome } & rpl36 & rpl33 & rpl32 & rpl23 & rpl22 & rpl20 \\
\hline & & rpl16 & rpl14 & $r p l 2$ & & & \\
\hline & RNA polymerase subunits & rроA & rрoB & rpoC1 & rрос2 & & \\
\hline \multirow[t]{9}{*}{ Photosynthesis } & Subunits of photosystem I & psaA & $p s a B$ & psaC & psaI & psaJ & \\
\hline & \multirow[t]{3}{*}{ Subunits of photosystem II } & $p s b Z$ & $p s b T$ & $p s b N$ & $p s b M$ & $p s b L$ & $p s b K$ \\
\hline & & $p s b J$ & $p s b I$ & $p s b H$ & $p s b F$ & $p s b E$ & $p s b D$ \\
\hline & & $p s b C$ & $p s b B$ & $p s b A$ & & & \\
\hline & Subunits of cytochrome & $\operatorname{pet} N$ & petL & $\operatorname{pet} G$ & petD & $\operatorname{pet} B$ & petA \\
\hline & Subunits of ATP synthase & atpI & $\operatorname{atpH}$ & atpF & $\operatorname{atp} E$ & $\operatorname{atp} B$ & atp $A$ \\
\hline & Large subunit of Rubisco & $r b c L$ & & & & & \\
\hline & \multirow[t]{2}{*}{ Subunits of NADH-Dehydrogenase } & $n d h K$ & $n d h J$ & $n d h I$ & $n d h H$ & $n d h G$ & $n d h F$ \\
\hline & & $n d h E$ & $n d h E$ & $n d h D$ & $n d h C$ & $n d h B$ & $n d h A$ \\
\hline \multirow[t]{7}{*}{ Other genes } & Maturase & matK & & & & & \\
\hline & Envelope membrane protein & $\operatorname{cem} A$ & & & & & \\
\hline & Subunit of acetyl-CoA & $a c c D$ & & & & & \\
\hline & C-type cytochromesynthesis gene & $\operatorname{ccs} A$ & & & & & \\
\hline & Protease & $\operatorname{clp} P$ & & & & & \\
\hline & open reading frames & $y c f 1$ & $y c f 2$ & $y c f 3$ & $y c f 4$ & & \\
\hline & Translational initiation factor & $\operatorname{infA}$ & & & & & \\
\hline
\end{tabular}

2 


\section{Figure 1}

Chloroplast genome map of $T$. candicans, S. transiliensis and T. yunnanense

Genes outside the circle are transcribed in a counterclockwise direction, while genes inside are transcribed in a clockwise direction. The darker gray belt in the inner circle refers to the GC content, and the lighter gray color refers to the AT content. Genes that have introns are marked with (*). SSC: small single copy; LSC: large single copy; IRA and IRB: Inverted repeats $A$ and $B$. 


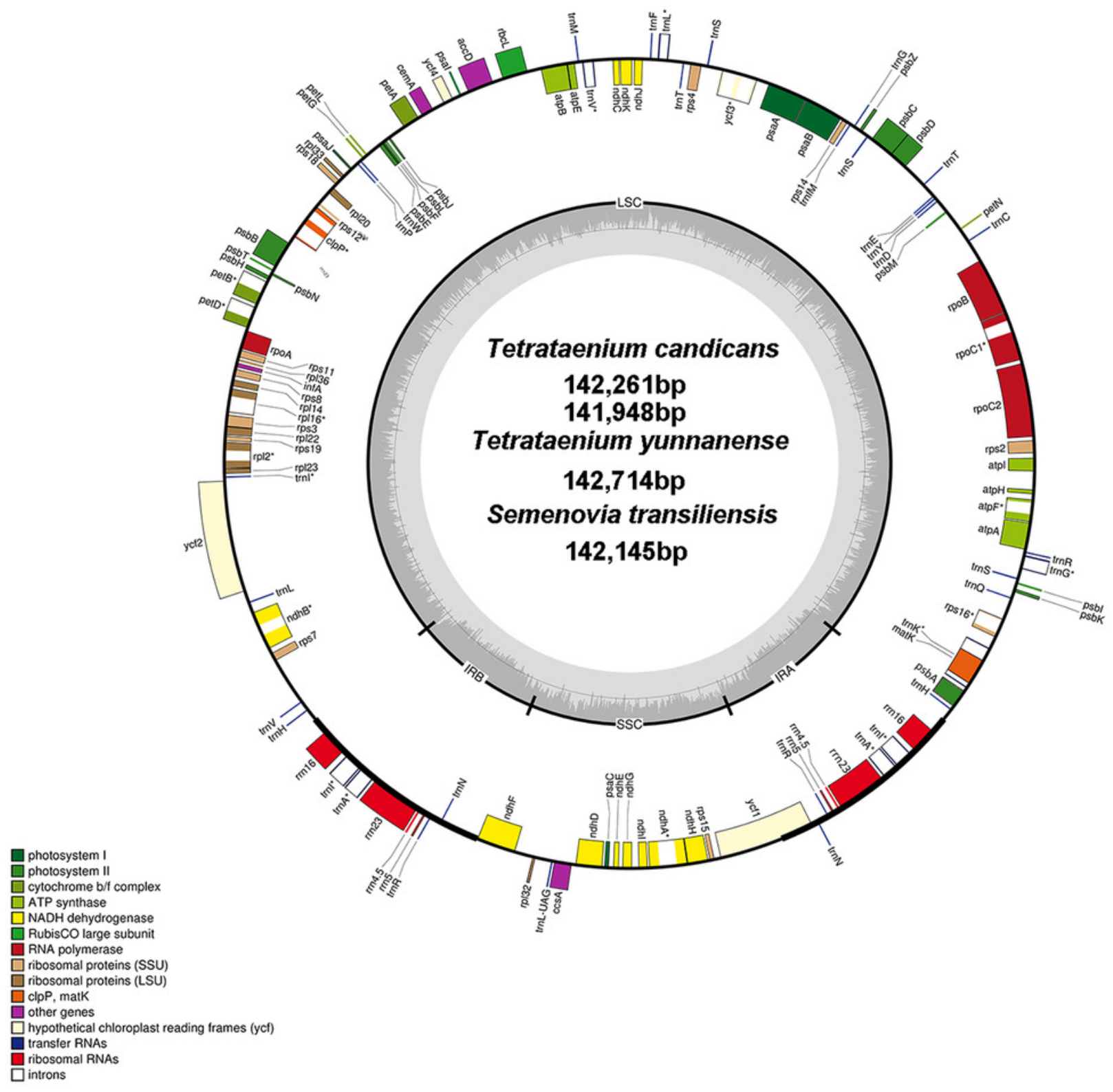




\section{Figure 2}

Comparison of the borders of the LSC, SSC, and IR regions of the chloroplast genomes of the five Tordyliinae species and Nicotiana tabacum

Genes beyond black lines are transcribed from right to left, genes over the black lines - from left to right. Each colored block represents a gene, and same color means same gene. The smaller blocks with the same color are truncated genes caused by shifting of IR boundaries. JLA: junction of LSC and IRA regions. JLB: junction of LSC and IRB regions; JSA: junction of SSC and IRA regions; JSB: junction of SSC and IRB regions.

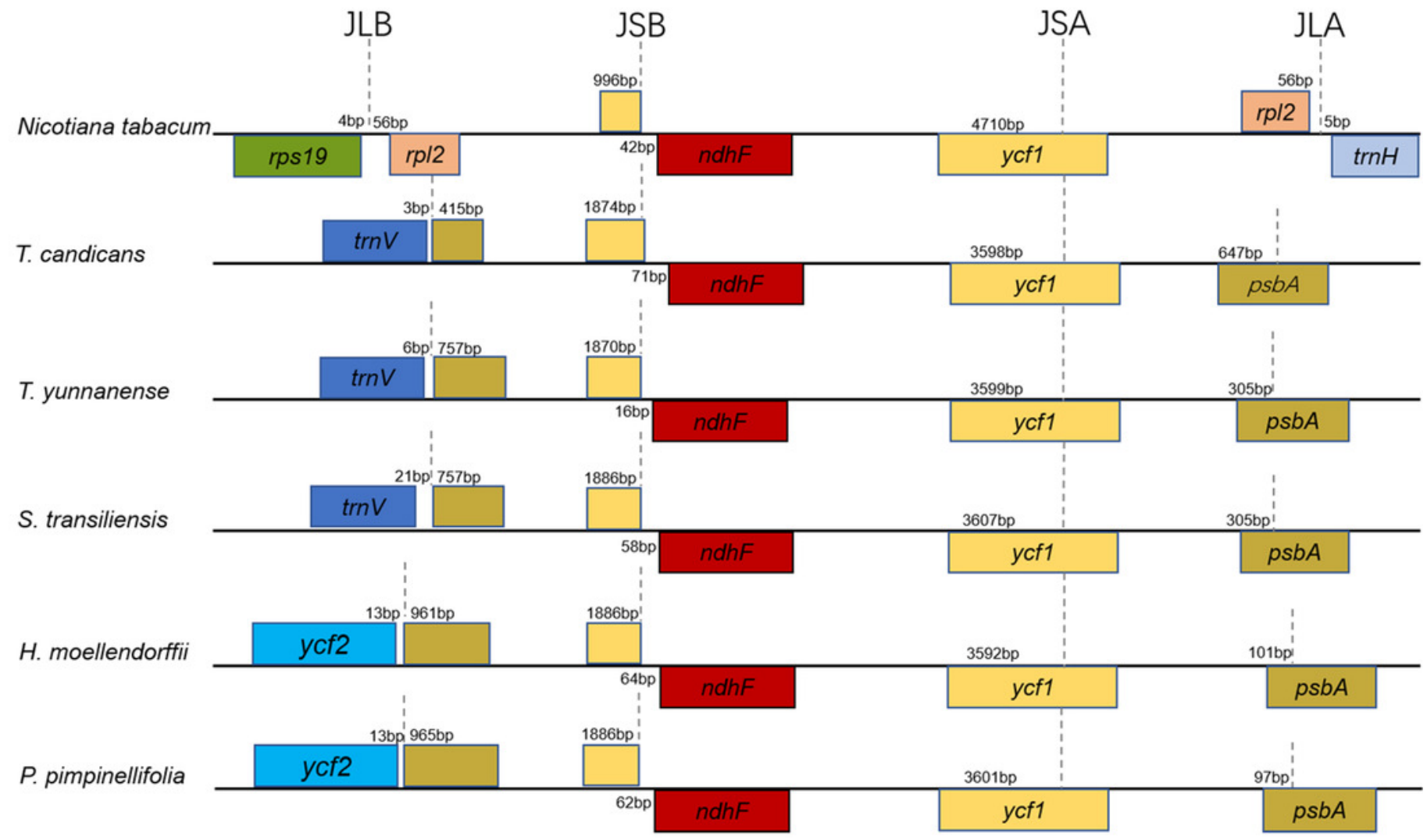




\section{Figure 3}

Numbes and repeat frequency of SSRs in five Tordyliinae species

(A-E) Number of SSRs in LSC, SSC and IR regions in plastomes of the five Tordyliinae species.

(F) Repeat frequency of different kinds of SSRs. Type C SSRs that blended more than one SSR type are calculated separately. Mono: mono-nucleotide]Di: di-nucleotides; Tri: trinucleotides; Tetra:tetra-nucleotides; Penta: penta-nucleotide; Hexa: hexa-nucleotides; C: compound SSRs. 

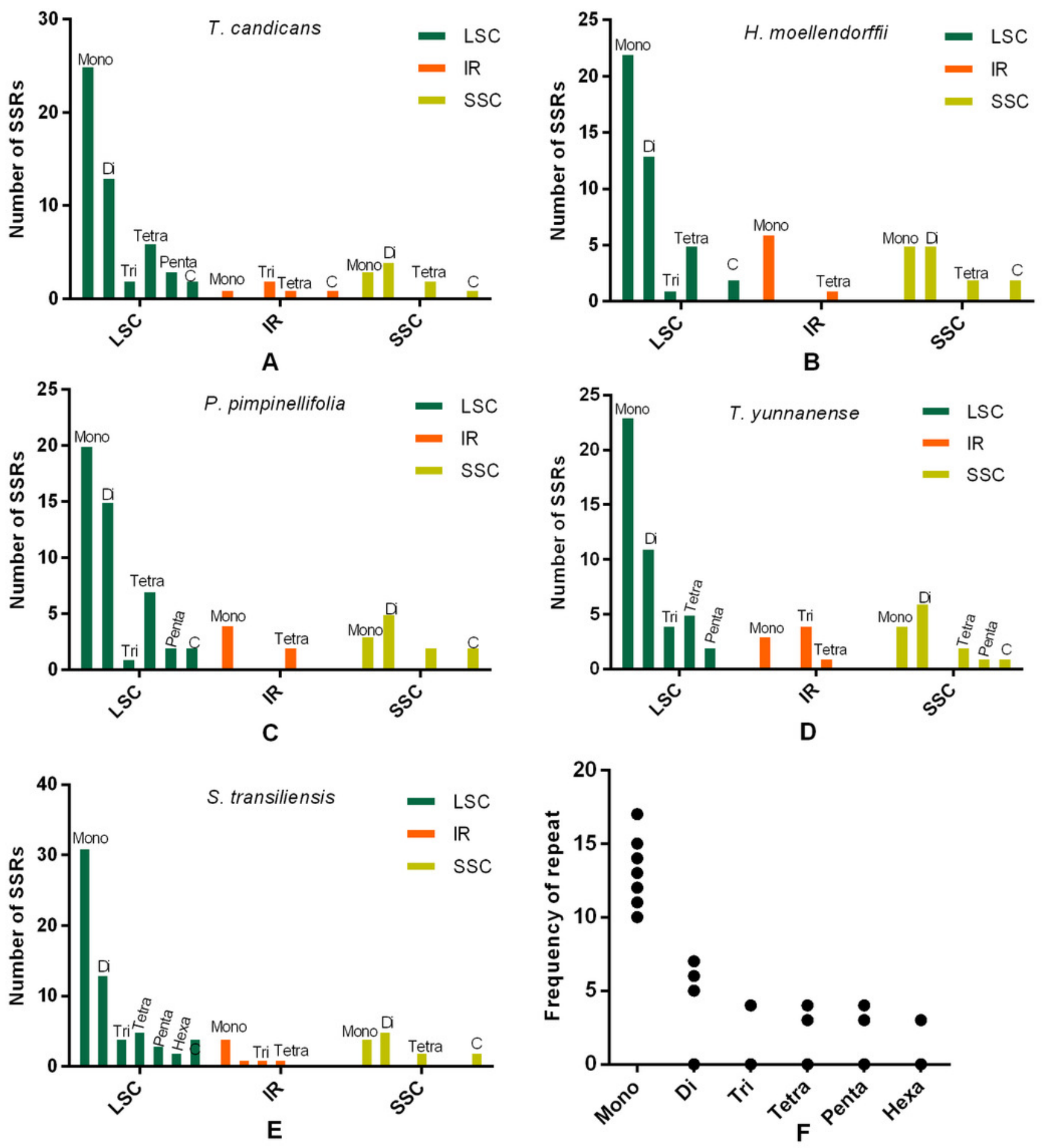


\section{Figure 4}

mVISTA visualization of alignment of $\mathrm{cp}$ genomes of Angelica sinensis and other six species

Blue blocks represent introns, orange blocks represent intergenic regions, and purple blockes represent exons. The locations of genes in cp genomes are shown below blocks, and sequence identity is shown on the right of blocks.Genes are marked with grey arrows, and arrows in forward direction represent genes are transcribed from left to right, otherwise from right to left. 

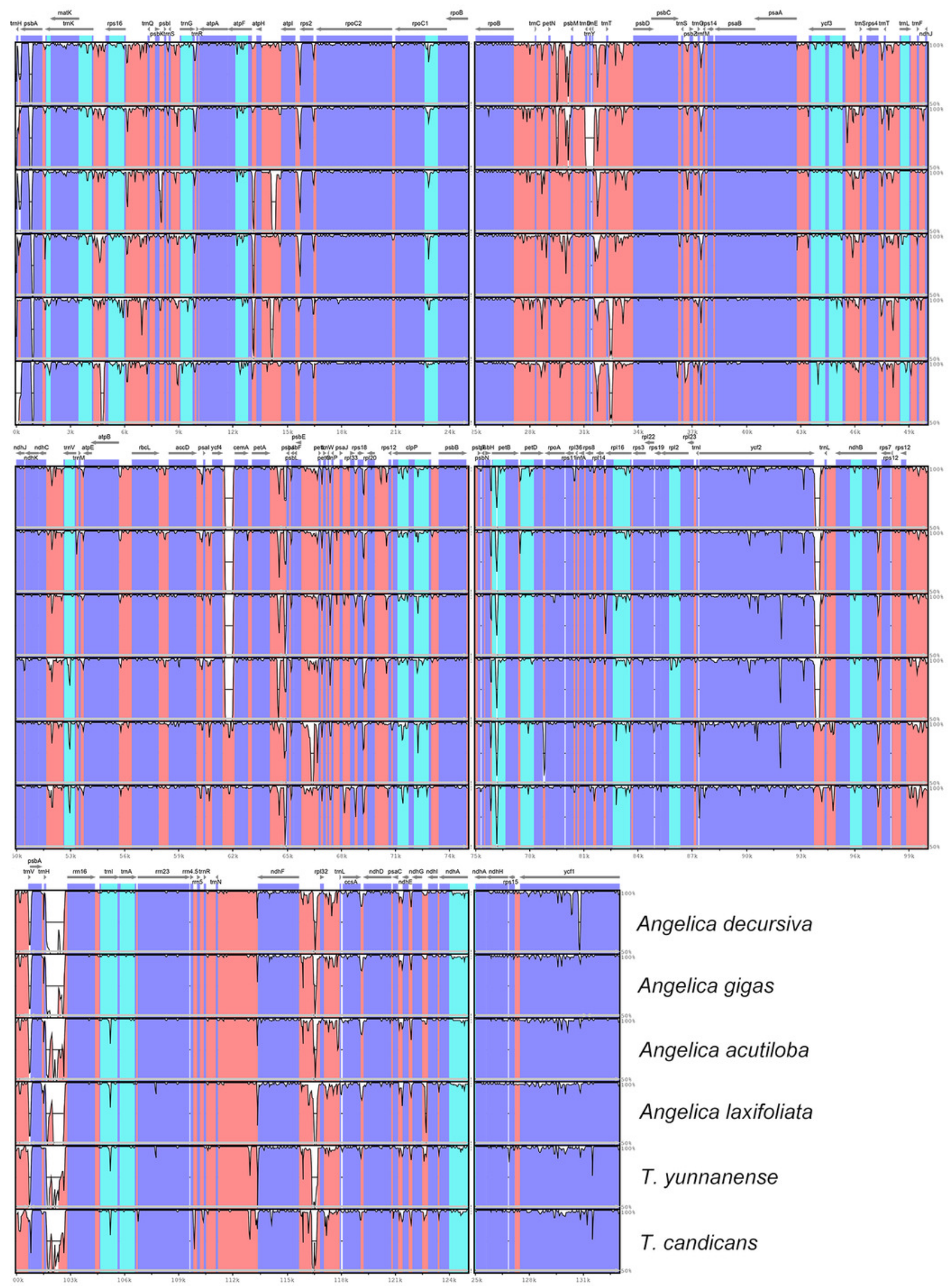

Angelica decursiva

Angelica gigas

Angelica acutiloba

Angelica laxifoliata

T. yunnanense

T. candicans 
Figure 5

DNA polymorphism of non-coding regions of chloroplast genomes of the five Tordyliinae species

(A) DNA polymprphism of non-coding segments at LSC (large single copy). (B) DNA polymorphism of non-coding segments at LSC, SSC (small single copy) and IR (inverted repeat) regions. Segments that marked with length and red dots are applicable for DNA markers. Pi value: nucleotide diversity value.
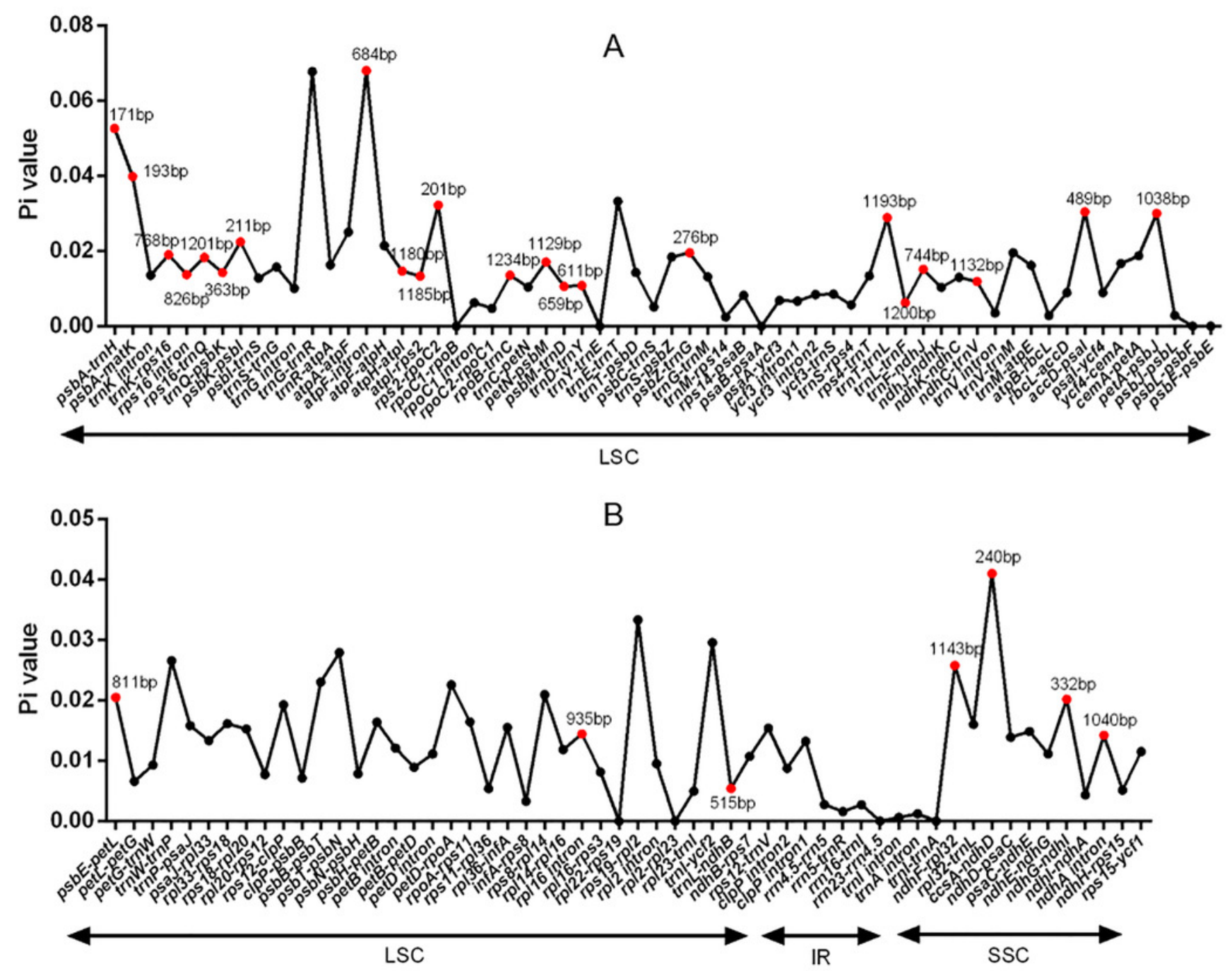


\section{Figure 6}

Maximum likehihood (ML) tree inferred from 80 concatenated protein coding sequences of 37 plastomes of Apiaceae and Araliaceae species

Bootstrap support values higher than $50 \%$ are indicated. The scale bar corresponds to 0.01 substitutions per site. Different clades or tribes are marked with colored line segments. Blue bar in the right of ML tree and grey block represent species from Apioid superclade.Species from tribe Tordylieae are colored red. 


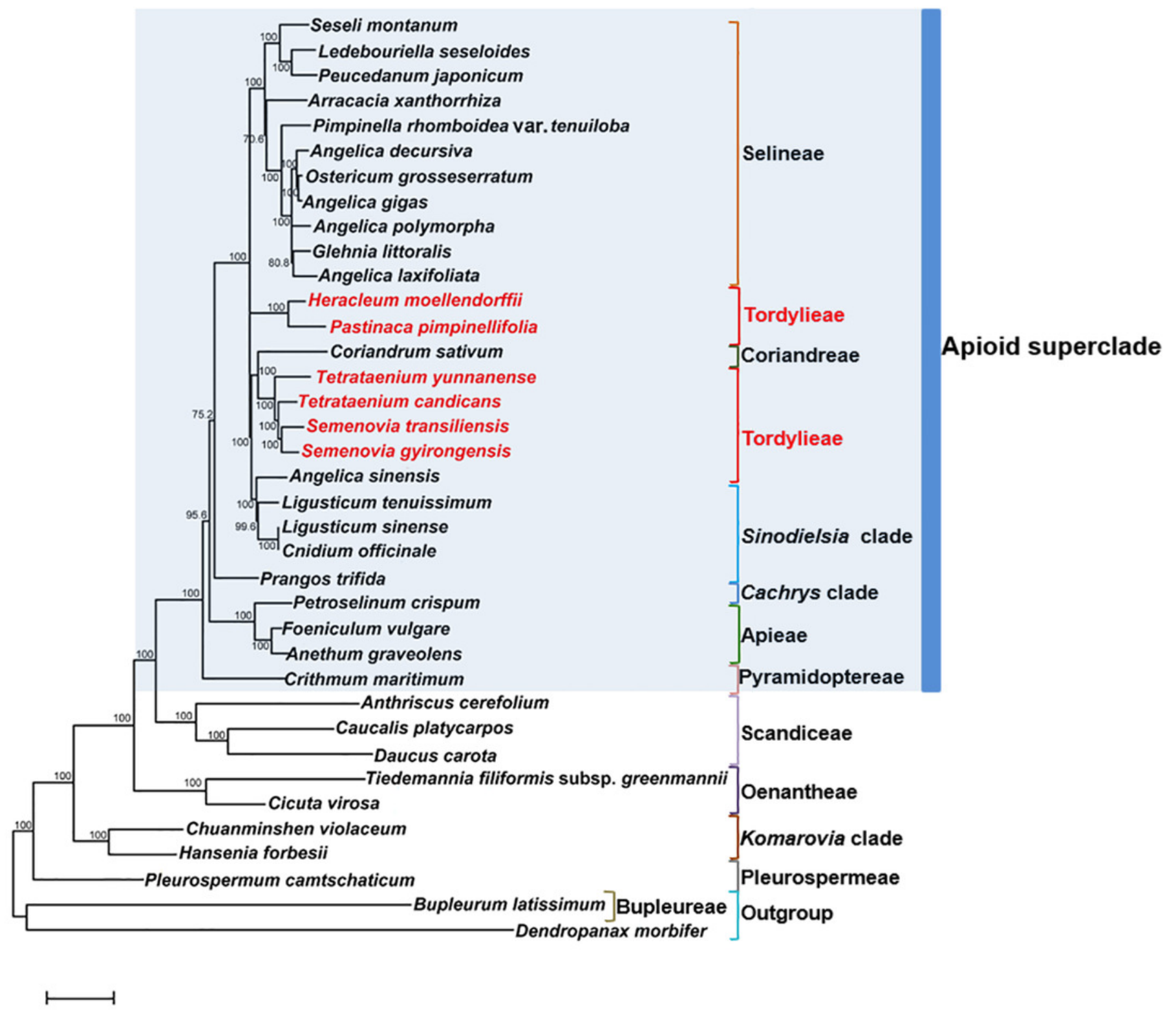

0.01 